\title{
The ability of adults of different size to egress through confined space apertures.
}

\author{
STEWART, A., NEVILL, A., JOHNSON, C.
}

2019 
The ability of adults of different size to egress through confined space apertures.

Arthur Stewart, ${ }^{1 *}$, Alan Nevill $^{2} \&$ Christopher Johnson ${ }^{1}$

${ }^{1}$ School of Health Sciences, Robert Gordon University, Aberdeen, UK.

${ }^{2}$ University of Wolverhampton, Faculty of Education, Health and Wellbeing, Walsall, UK

Running Head: Egress through confined space apertures

Manuscript type: Research Article

Word Count: 3755

*Corresponding author: Arthur Stewart

School of Health Sciences, Robert Gordon University

Office N546, Sir lan Wood Building

Garthdee Road

Aberdeen

AB10 7GJ

UK

+44(0)1224 262551 a.d.stewart@rgu.ac.uk orcid.org/0000-0002-4407-0946

Acknowledgements: No funding was received in support of this study

Short Abstract / Précis

Absolute body size is a strong predictor of minimum wall aperture transit in adults. Key anatomical dimensions scale to egress capability, but men and women exhibit subtle differences. Wherever clearance space is restricted, transit capability is likely to become increasingly limited by enlarged body size associated with increased obesity prevalence. 


\section{Abstract}

Objective: To determine minimum egress apertures in healthy adults of different body size.

Background: Body space requirements have traditionally been considered from an industrial perspective, facilitating safe confined-space working. However, increased typical body size resulting from global obesity renders traditional assumptions of body size inappropriate. This has potentially far-reaching consequences for evacuation planning, due to diminished clearance space, slower movement, and increased chance of physical entrapment. Critically, no current literature describes the minimum apertures adults can negotiate.

Method: Forty-eight men and 40 women underwent anthropometric and 3D scanning assessments from which anatomical dimensions were extracted. Additionally, a wall egress task was undertaken through an aperture that was progressively narrowed until individuals failed to pass. Minimum egress aperture was predicted from anatomical variables using backwards elimination regression.

Results: Minimum wall egress was best predicted from mass, abdominal depth, bideltoid breadth and chest depth. Passes and fails, discriminated using binary logistic regression, identified chest depth and abdominal depth as influential for wall egress success at selected apertures, with a gender interaction manifest at abdominal depth.

Conclusion: Minimum egress aperture relates to body size and can be predicted from anatomical variables; however, men and women display subtle differences in egress capability.

Application: In public and industrial settings, egress capability in restricted spaces is affected by size and gender, with profound implications for safety, which relate to increased typical body size associated with global obesity.

\section{Key words}

Anthropometry; extreme environments; pedestrian safety; architecture; gender 


\section{INTRODUCTION}

Restricted space imposes physical constraints on the ability of a person to access and egress spaces within buildings or transportation in public, occupational and military sectors. Such constraints may not affect movement patterns for all individuals, or may be accommodated by behaviours such as waiting or queueing. However, in an emergency situation, restricted space has the potential for serious consequences by affecting the flow of individuals along a route, the ability of individuals to pass one another in counter-flow, or their ability to pass through a bottleneck or narrow aperture.

Fruin (1971) defined space requirement for pedestrians from the $95^{\text {th }}$ centile male shoulder breadth and body depth, allowing $13 \mathrm{~cm}$ for lateral sway and $15 \mathrm{~cm}$ clearance from vertical surfaces. Work by (Manenti et al., 2010) subsequently highlighted situational space preferences, identifying proximity zones like shells around individuals for public, social, personal and intimate settings. Closer proximity increases crowd density and those above 4 persons $/ \mathrm{m}^{2}$ unavoidably involve physical contact between adults (Still, 2013). Modelling movement is infinitely more complex than modelling static individuals. This wide-ranging research effort has examined speed and spacing preferences (Willis et al., 2004), group structures (Qiu \& Hu, 2010), channel flow at a bottleneck (Tajima et al., 2001; Nicolas et al., 2017), bi-directional body turning (Jin et al., 2017) queueing behaviour (Hu et al., 2018), obstacle negotiation (Zhao et al., 2017) and escape panic (Helbing et al., 2000). Hitherto, research determining minimum apertures capable of negotiation is conspicuously absent from this wider literature.

Although public settings rarely encompass such restricted space, a significant exception might be certain types of historic building never designed for mass visitation, yet now host increasing numbers of tourists. Such buildings frequently have archaic layouts, steep staircases, narrow passageways and limited ambient lighting (Stewart \& Campbell, 2018), and while these may present little challenge to 
healthy, able-bodied individuals, they may be less easily negotiated by larger and older individuals. Not only is walking speed substantially reduced with age (Bohannon, 1997) and obesity (Spyropoulos et al., 1991), lateral movement increases and obstacle avoidance tactics alter in confined spaces (Hackney \& Cinelli, 2011; Warren, 2007). The ability to negotiate narrow apertures is affected by perceptual factors such as age-related decrements in vision (Loh \& Ogle, 2004) and vestibular function (Iwasaki \& Yamasoba, 2015). In addition, tactical and experiential factors affect outcomes, and in empirical research on aperture negotiation have been described by probabilistic functions (Franchak and Adolph, 2014a), adaptive to changes in body size (Franchak \& Adolph, 2014b) and space availability of the body in motion (Franchak et al., 2012).

To determine how much space is required for a person, the classic ergonomic approach to 'design for sustainability' is to consider the anthropometry of the user population (Nadadur \& Parkinson, 2013). However this 'problem statement' becomes inverted for egress research where clearance space - the distance between a person and the inner surface of space occupied - critically affects movement capability (Stewart, 2016). Clearance space is reduced in an anatomically larger host population which, combined with congestion, dramatically affects evacuation efficiency (Galea et al., 2008). Analysis of clearance space can assess the point at which passing ability and counter-flow is compromised (Stewart et al., 2015), and, more poignantly, where egress itself becomes impossible. While minimum egress aperture has been quantified using a frame transit approach to simulate hatch and window egress in aviation (Allan \& Ward, 1986; Stewart et al., 2016) there appears to be no comparable evidence regarding minimum wall egress. Furthermore, there is no evidence to suggest design standards based on absolute size affect men and women equally. Therefore, this study aimed to address this knowledge gap by aiming to investigate egress capability through restricted wall apertures in a group of adult men and women of differing body size. Specific objectives included to devise a predictive model for minimum egress apertures based on anatomical dimensions; to 
characterise those who are successful and unsuccessful at specific egress apertures, and to compare egress performance between men and women.

\section{METHODS}

Participants were primarily recruited from the general public as well as manual and academic university staff and students. A convenience sample of 88 adults comprising 48 men and 40 women ranging from underweight to obese was recruited using poster and email advertisement. Physical characteristics of the sample are summarised in table 1 . The lack of previous comparable studies precluded a statistical power calculation for sample size.

Participants undertook three types of measurement in a single session lasting approximately 15 minutes. The measurement battery was configured to optimise key data acquisition and participant recruitment.

1. Anthropometric dimensions. Stature was acquired on a stadiometer and clothed mass (with shoes removed) was obtained on a digital weighing scale (Seca models 230 and 813 respectively, Hamburg, Germany). Torso dimensions were obtained using a Campbell 20 large sliding caliper (Rosscraft, Vancouver, Canada) and included bideltoid breadth (Stewart \& Hume, 2014); chest depth (Stewart \& Hume 2015); anterior-posterior abdominal depth and bicristal breadth (Stewart et al., 2011). All measurements were made by a level 4 criterion anthropometrist of the International Society for the advancement of Kinanthropometry.

2. Body scanning. A 3D body scan was acquired using a Hamamatsu BLS 9036B scanner (Hamamatsu, Japan), or an Artec L (Artec Group, Luxembourg) and processed by proprietary software (Body Line Manager 1.3 or ArtecStudio 9, respectively). Both scanners have been previously cross-calibrated 
(Ledingham, Nevill \& Stewart, 2013)]. Participants wore form-fitting clothing which exposed the shoulders, and held their elbows against the side of the torso, with hands against the lateral thighs in a mid-prone position (thumbs forward). The scan was acquired at the end-tidal position, and the inferior margin of the deltoid muscle identified. Extracted measurements were selected because of their influence over egress capability and included bideltoid breadth, and two chest depth measurements: A) the largest horizontal distance in the sagittal plane across the thorax) and B) the perpendicular planar distance between the most anterior and posterior points on the thorax. Because these points may not align, two different measurements of chest depth were acquired. Duplicate scans were acquired in 20 individuals in order to quantify inter-tester error, and extracted measurements were made independently by two members of the research team.

Scan analysis procedure. For measuring the bideltoid of the scan image, the first stage was to enlarge the image so that the shoulders filled the screen in a coronal plane view. The image was rotated about a vertical axis as required to observe the curvature of the left and right deltoid, and the landmark was placed on the most lateral point of each, with system software calculating the Euclidian distance between the two. Anthropometric measurements and extracted dimensions from scans are illustrated in figure 1.

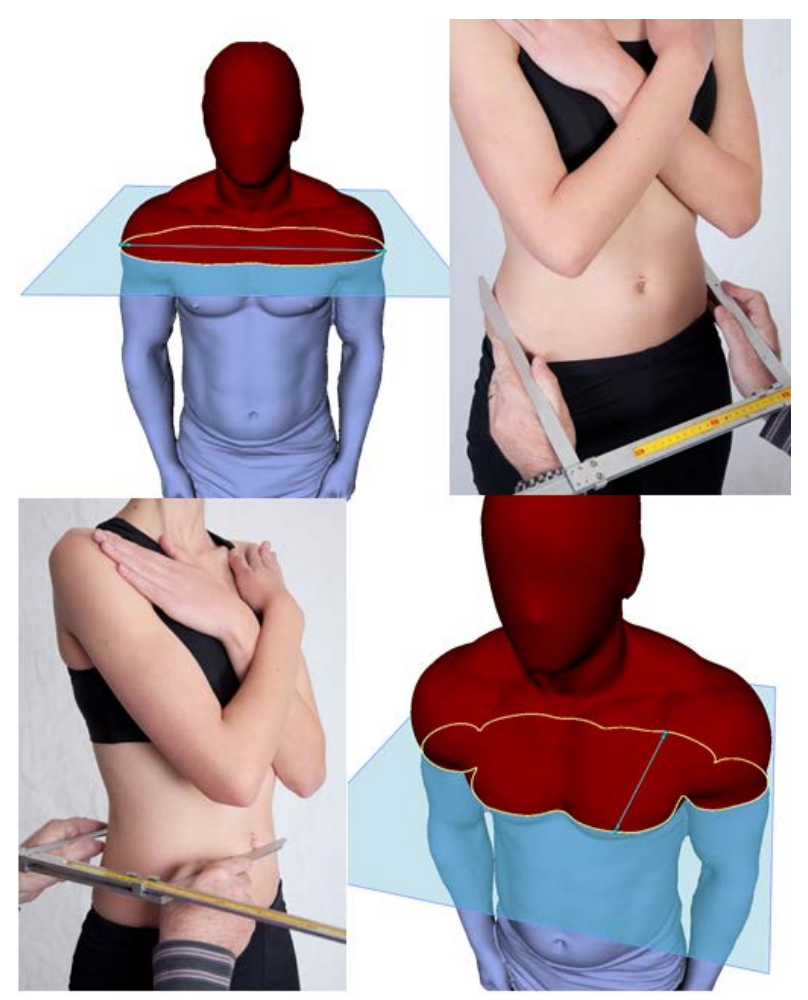

Figure 1. Upper L: bideltoid breadth; R: bicristal breadth Lower L: abdominal depth; R: chest depth 


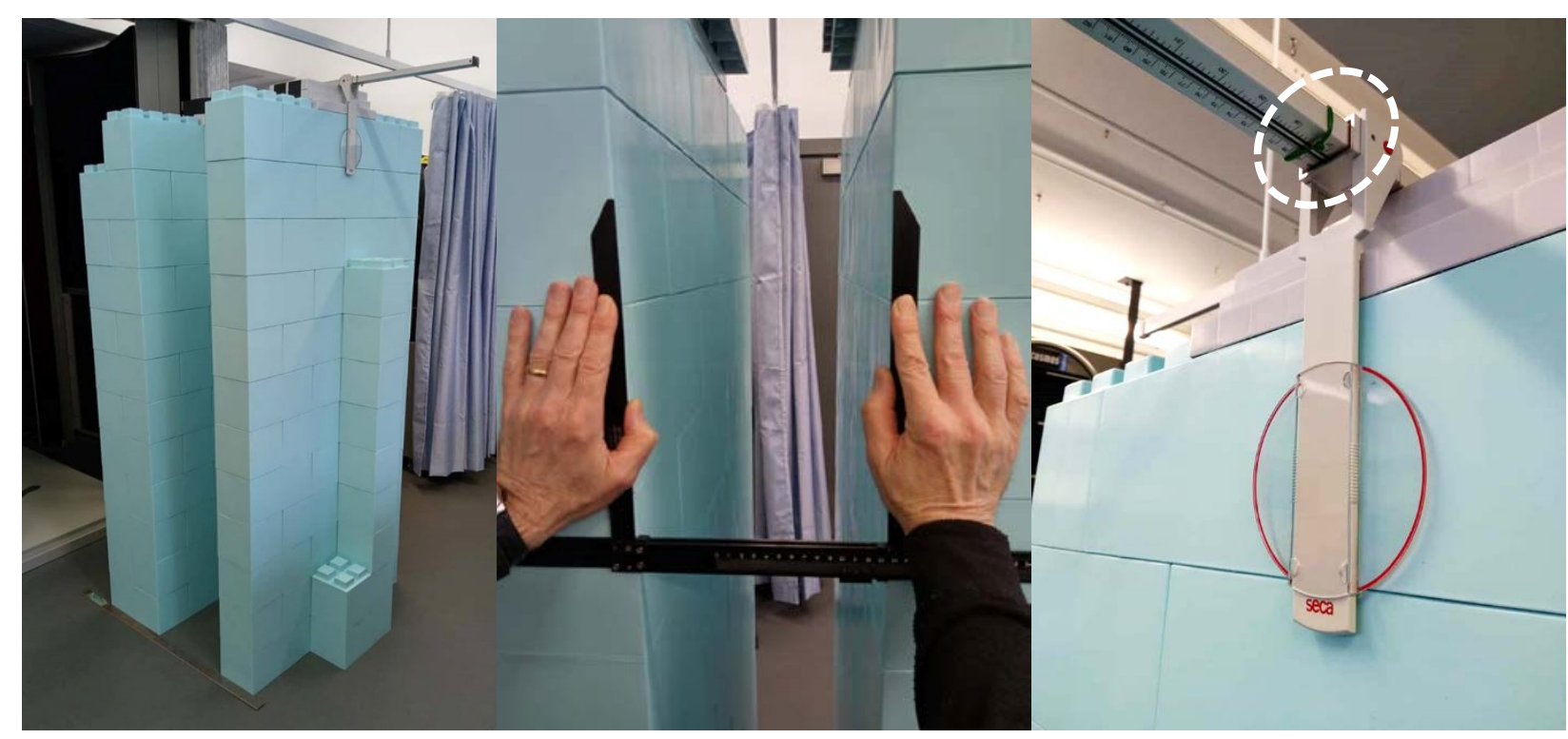

Figure 2. L: Egress wall assembly; centre: varying the wall separation; R: caliper detail showing cursor which detects displacement (white ellipse).

3. Wall egress. The wall egress test was assembled as shown in figure 2 . As illustrated, the walls were made from plastic partitioning bricks (Everblock systems, Bishop Auckland, UK) providing a rigid surface that was sufficiently light to prevent the participant from becoming trapped when performing the test. Parallel walls were set in place at a fixed separation corresponding to integer distances in $\mathrm{cm}$ narrowly exceeding the participant's chest depth. The participant then progressed between the walls without dislodging the movement sensor (a customised SECA large sliding caliper, model 207, SECA, Hamburg, Germany) which determined the extent of perturbation of the walls resulting from horizontal pressure exerted by the participant (see figure 2, R). A displacement of $10 \mathrm{~mm}$ or less (equating to a horizontal force of approximately $80-120 \mathrm{~N}$, established via application of a force transducer, depending on how far above the floor the force was applied) was deemed necessary to consider the trial a pass, while greater amounts resulted in a fail. Three attempts were allowed at any wall separation. The starting separation between the walls was determined from adding $2 \mathrm{~cm}$ to the participant's chest depth, assessed anthropometrically. Participants performed the test, taking $5-10 \mathrm{~s}$ for each trial. After successful egress, the walls were narrowed by $1 \mathrm{~cm}$ and the process repeated until the participant perturbed the walls by more than $10 \mathrm{~mm}$. 
Statistical methods. Backwards elimination regression analysis was performed on log-transformed dimensional variables using SPSS v 21 (Chicago, USA), to predict the minimum egress wall separation and window diagonal from anatomical variables. Binary logistic regression was used to explore which key physical characteristics could predict the odds of failing to pass through apertures at median values for the wall and window tests.

All participants provided informed consent, and the study was approved by the School Research Review Board.

\section{RESULTS}

Participants' physical characteristics are summarised in table 1.

Table 1. Participants' physical characteristics

\begin{tabular}{lcccc} 
& Male $(n=48)$ & Female $(n=40)$ & Total $(n=88)$ & range $(n=88)$ \\
\hline Age $(y)$ & $27.8 \pm 10.2$ & $32.0 \pm 10.2 \dagger$ & $29.7 \pm 10.4$ & $18-57$ \\
Stature $(\mathrm{cm})$ & $177.1 \pm 7.0$ & $165.8 \pm 6.0^{* *}$ & $172.0 \pm 8.6$ & $154.5-193.5$ \\
Mass $(\mathrm{kg})$ & $82.6 \pm 16.8$ & $66.7 \pm 10.3^{* *}$ & $75.3 \pm 16.3$ & $53.2-129.9$ \\
BMI $\left(\mathrm{kg} \cdot \mathrm{m}^{-2}\right)$ & $26.2 \pm 4.5$ & $24.2 \pm 3.7^{*}$ & $25.3 \pm 4.3$ & $18.4-41.1$ \\
\hline
\end{tabular}

Values represent mean \pm SD; + NS; Different from males $* P<0.05 ;{ }^{* *} P<0.001$

The reproducibility error of measurements is summarised in table 2 .

Table 2. Percentage technical error of measurements of replicated measurements

\begin{tabular}{lcccc} 
variable & $\begin{array}{c}\text { Same scan } \\
\text { intertester } t\end{array}$ & $\begin{array}{c}\text { Diff scan } \\
\text { intratester* }\end{array}$ & $\begin{array}{c}\text { Diff scan inter } \\
\text { tester } \phi\end{array}$ & $\begin{array}{c}\text { Anthro } \\
\text { intertester } \psi\end{array}$ \\
\hline Bideltoid & 0.69 & 0.71 & 0.93 & 0.34 \\
Chest depth phys. & 1.23 & 0.90 & 1.23 & 1.07 \\
Chest depth perp. & 1.12 & 0.87 & 1.21 & Not done \\
Abdominal depth & Not done & Not done & Not done & 1.35 \\
Bicristal breadth & Not done & Not done & Not done & 0.88 \\
\hline
\end{tabular}

Phys: physique method; perp: perpendicular method; $+n=43 ;{ }^{*} n=22 ; \phi n=44 ; \Psi n=14$;

\section{Data treatment for modelling}

All predictor data were log transformed prior to undertaking regression analysis, due to heteroscedacity. Furthermore, all variables were assigned a gender interaction term to allow for the possibility that male and females differ in egress capacity due to a factor other than overall size. 


\section{Predictability of wall egress.}

The minimum aperture successfully egressed was used as the dependent variable in the regression, for both the wall egress test.

A backwards elimination linear regression of minimum wall egress capability produced the following regression $(n=88)$ :

Ln minimum wall egress $(\mathrm{cm})=0.334 \ln M+0.246 \ln A D-0.284 \ln B D s+0.406 \ln C D p e+1.157\left(R^{2}=\right.$ 0.91; SEE=0.036; $P<0.0001)$

where $\mathrm{M}=$ mass $(\mathrm{kg}) ; \mathrm{AD}=$ abdominal depth $(\mathrm{cm}) ; \mathrm{BDs}=$ bideltoid breadth from scan $(\mathrm{cm}) ; \mathrm{CDpe}-$ chest depth perpendicular from scan $(\mathrm{cm})$

A summary of minimum wall egress in relation to chest depth is depicted in figure 3.

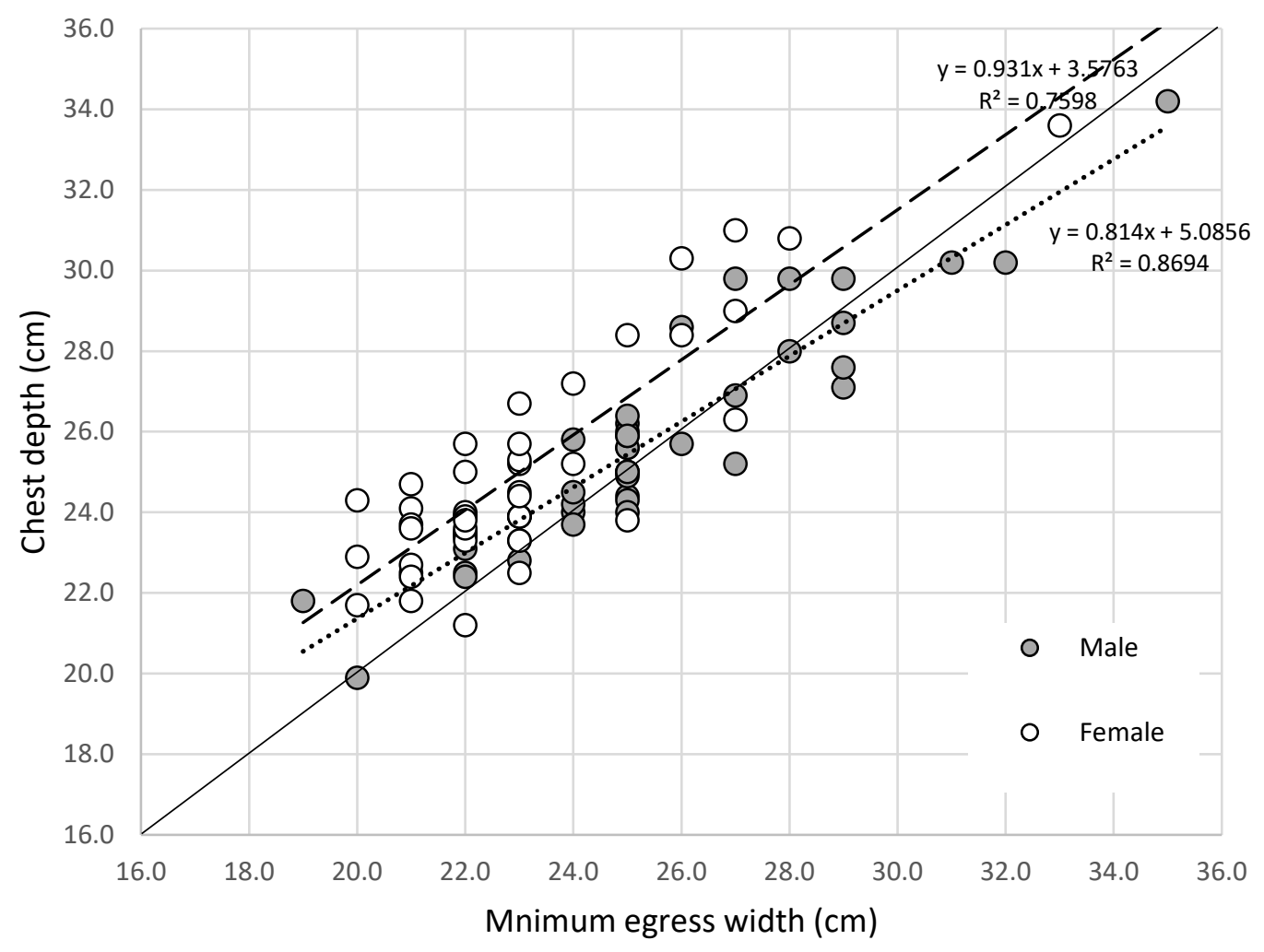

Figure 3. Wall egress capability (solid line represents line of identity)

The difference between minimum wall separation successfully egressed from measured chest depth was typically $1.6 \mathrm{~cm}$ greater for women than men $(95 \% \mathrm{Cl} 1.0-2.1 \mathrm{~cm} ; \mathrm{P}<0.0001)$ 


\section{Comparison of passes and fails.}

Wall egress was set at the median value of $23.5 \mathrm{~cm}$. 15 men and 29 women passed, while 33 men and 11 women failed. Table 3 describes the odds of failing to egress through this wall separation.

Table 3. The key physical characteristics associated with failing to egress through the $23.5 \mathrm{~cm}$ wall gap

\begin{tabular}{cccccc} 
& & & Odds Ratio & \multicolumn{2}{c}{$95 \%$ C.I. for the OR } \\
& B & Sig. & (OR), exp(B) & Lower & Upper \\
\hline Abdominal depth & 1.220 & .013 & 3.386 & 1.299 & 8.827 \\
$\begin{array}{c}\text { Chest depth perp } \\
\text { Female abdominal }\end{array}$ & 1.824 & .005 & 6.197 & 1.737 & 22.112 \\
$\quad$ depth & -.163 & .026 & .850 & .736 & .981 \\
$\begin{array}{c}\text { Constant } \\
\chi^{2} \text { test for model } \\
\text { coefficients }\end{array}$ & -70.860 & .001 & .000 & & \\
\hline
\end{tabular}

Lastly, passes and fails for the wall egress median values were compared for a range of dimensions. Standardised effect sizes were calculated which are depicted in figure 4, illustrating a hierarchy of parameters which range between maximally and minimally different between the groups. 


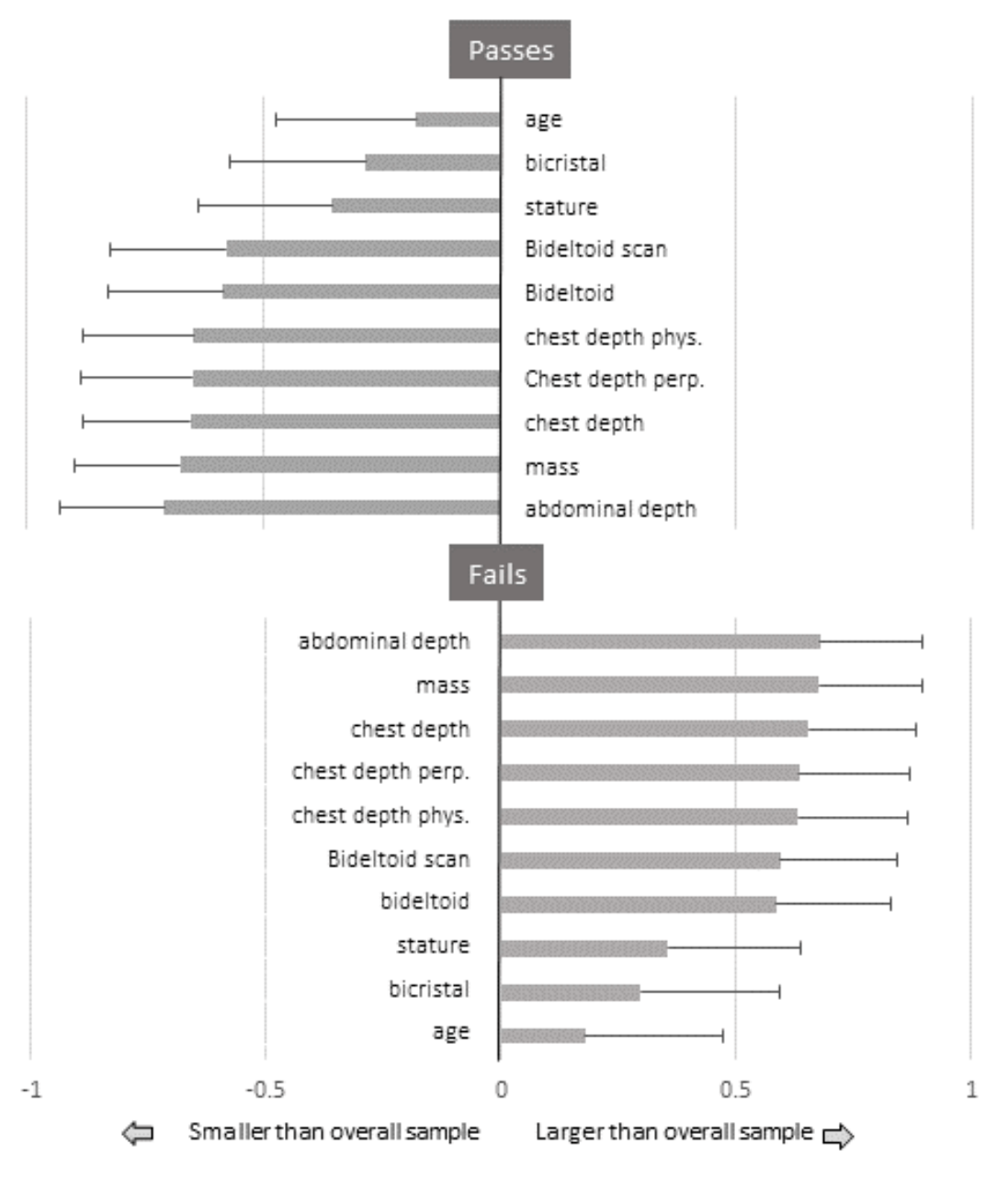

Figure 4. Standardised effect sizes of passes $(n=44)$ and fails $(n=44)$ for a wall separation of $23.5 \mathrm{~cm}$ as compared with the entire sample. Error bars show $95 \% \mathrm{Cl}$. Variables with a greater horizontal distance between passes and fails indicate their greater capacity to discriminate between them in a predictive test.

Taken together, the gender differences in individual dimensions (e.g. chest depth) with respect to wall egress, as well as absolute body size have important implications which will be expanded in the discussion .

\section{DISCUSSION}


The main findings of the study show that egress capability can be predicted from body dimensions. In an optimised prediction of wall egress capability, males and females respond broadly similarly, but display a subtle difference regarding abdominal depth.

The results appear somewhat counter-intuitive. Morphological differences of the torso between men and women could conceivably influence degree of chest compression imposed by rigid external surfaces. Given that adipose tissue has demonstrated lipid to be highly compressible (Toomey et al., 2011), we hypothesized compression might be greater for females than for males, due to its abundance in the breast morphology. However, the results for wall egress do not support this, as neither gender nor the gender interaction terms were selected in the optimised model. As figure 3 illustrates, the relationship between chest depth and minimum egress width is similar for men and women, with women typically achieving lower aperture egress than men.

\section{What this study adds to egress research.}

This study contributes new and important information to egress research. There are a number of approaches to egress research, mostly developed for emergency building escape, which use techniques such as agent-based modelling, fluid dynamics, or other mathematical approaches which model the behaviour of large groups of individuals. In a fire scene simulation model, factors such as visibility, air quality, building geometry and person density are modelled, and unlike horizontal evacuation of floors within a building, stair evacuation is considered a serial process (Tang \& Ren, 2008). In particular, various aspects of human behaviour are required to interact with the changing circumstances of the developing fire. These mandate a systems approach, and include not only physical factors such as movement speed, visibility, heat load etc. during combustion but also behavioural factors such as reaction time, collaboration, insistence (the probability of maintaining a current evacuation strategy) and knowledge and familiarity with the building which inform decisions. Visual guidance for walking through narrow apertures regarding perception of space, and judgement whether or not it was 
passable show body-scaled information informing movement decisions (Warren \& Whang, 1987), highlighting the inconvenience and potential hazard of outdated size specifications for corridor width for individuals. In an emergency or mass evacuation, the situation becomes infinitely more complex. Research which modelled the World Trade Center disaster (Galea et al., 2008) utilised software to involve staircase packing to its full capacity, and accounted for contra-flow of fire-fighters ascending stairs with equipment as evacuating employees descended. In reality, structural damage and debris will inhibit egress, and may create physical barriers which may create narrow apertures for individuals escaping. However, the available models presume individuals egressing fit through the exits and do not consider those who 'only just fit' and 'do not fit' which have the potential to retard or arrest egress through an aperture, and consequential re-direction of flow of individuals. While research has long recognised a size-dependency of normal locomotion, hitherto, little has been known about the sizedependency of egress, which, in restricted space, has the potential to be more influential than crowd density. This is because of the likelihood of individuals at the egress point undergoing a trial and error process before escaping through a limited aperture, or, in the event of failure, having to make way for others.

\section{Strengths and weaknesses}

This study has modelled egress in a mixed gender group ranging from underweight to morbid obesity. It has used convenience sampling and based its findings on anatomical size. Despite participants ranging in age between 18 and $59 \mathrm{y}$, the study has not, however, sought to replicate a truly representative sample of a wider ambulatory population. Had this been attempted, the sample would have necessarily included both children and the extreme elderly, many of whom would be likely to have health conditions such as hypertension, or low bone density, which could have placed them at risk if they had participated and, as such, prohibited by the University ethics review board. 
It is not possible to re-create a genuine emergency situation in a laboratory setting. Various attempts to consider the way the public may evacuate areas have been attempted (for summary see Schadschneider et al., 2011). Financial incentives to create a competitive situation in egress have been successfully implemented in aviation research (Wilson, 2008), but these have been applied to standardised apertures which prevail within the industry. While this may have fallen short of a panic where stampede behaviour has been reported in genuine disasters (Still, 2013), even this approach mandated first aid provision in order to satisfy safety concerns and ethics permission, even though no injuries were recorded in the experimental trials. In the present study, a rigid aperture, for the experimental design for the wall egress was not used in order to facilitate the structure failing with the application of sufficient force, so the participant could emerge unharmed. Because of this capacity built into the wall egress experimental set-up, the true minimum egress apertures achieved may be even less than recorded here.

Selection of median values for comparing passes with fails sought to balance the numbers to make a meaningful comparison. The reality is that had a different threshold been selected, not only would the pass - fail numbers have been more unbalanced, but the selected variables which discriminated between the two would likely differ. Future work could usefully consider this, as well as additional factors such as limited visibility or egress with hand-held items or backpacks. It could also assess the motivation for success, and acquire a full stratified sample of the public. However, such a definitive study would require considerable resource, and it must be borne in mind that in reality, public buildings such as ancient monuments do not necessarily attract a representative demographic sample of the wider population on any given occasion. This is due to the selectivity imposed on those present being limited by factors including working hours for those in employment, or the scheduling of visitor tours. 
No comparable study to the present one has previously been published. The data presented here can be used as a baseline value for understanding of human capabilities in terms of egress, and also for generating an understanding of passing potential in narrow corridors. Our previous modelling work which was based on the body as a rigid object (Stewart et al., 2015) can now be enriched with a compressibility factor from its outermost dimensions (bideltoid breadth and chest depth) to produce an enhanced egress model.

\section{Practical Implications}

Men and women behave broadly similarly with respect to wall egress, but may be differently affected by abdominal depth. Historic guidelines and legislation based on size alone are inappropriate, because our data show that in some cases it is unsafe to assume females as smaller sized males when they negotiate physical obstacles. This not only affects egress, but also and passing ability within a complex space. Until recently, the US Department of Energy (2001) utilised a preferred face-to-face horizontal clearance of $0.81 \mathrm{~m}$ for standing operations to enable passing, with a minimum of $0.51 \mathrm{~m}$ (DOE, p 116). The former theoretically equates to more than double the male $95^{\text {th }}$ centile anterior-posterior depth, while the latter would be just less than double the mean value (Peebles \& Norris, 2002, protocol 68). However, clearance dimensions measured as a perpendicular between two planar surfaces (see Pheasant, 2003, p 47.) exceed those of a linear depth across the thorax, because of the requirement to stand or move sideways in balance during passing. Three further aspects require consideration. Firstly, chest depth in females exceeds that in males by between 10 and $20 \%$ across different national surveys (Peebles \& Norris, 2002) and the difference appears to be exacerbated in larger individuals. This may have been overlooked in industrial settings which may have historically based guidance on male data and also may have failed to recognise that females may seek an enlarged personal space requirement for passing without contact, relative to males. While this study did not set out to derive data for a design standard, it has created new knowledge which could be used along with other information such as visitor numbers to consider if visitor body size could affect operational safety. Secondly, while it is 
recognised that industrial clothing increases space requirements by a measurable amount over that for form-fitting clothing (Stewart et al., 2015) and varies by clothing type (Kozey et al., 2008), it is unknown how variable the clothing thickness is between different members of the public, in different climates and seasons. Thirdly, a normal tactic of turning sideways to reduce space requirement, as considered in the case of pregnant women (Franchak \& Adolph, 2014) becomes progressively more redundant with increasing levels of obesity, due to the body depth approaching and exceeding its width.

Crucially, there appears to be a conspicuous disconnect between industrial recommendations for access of professional workers, and the general public's use of buildings which may well include restricted space. The evidence-base for such recommendations was largely informed by limited research conducted when typical body size was considerably smaller than that of today. Furthermore, in historic buildings, where overtaking is not feasible, position in the egress line critically affects the time taken to exit because egress speed is determined by that of the person in front (Stewart et al., 2017). The present study adds to this critical understanding and also lays the ground work for passing ability calculation based on real trials which include an element of compressibility, as opposed to treating the body as a rigid shell. This could prove useful in understanding critical events when a situation transcends 'normal building operation', for instance in the event of a medical emergency, fire or terrorist incident. There is also potential for egress paths to be restricted by debris following structural damage, with the result that clearance space and movement capability become reduced further. However, no previously published data exist which could cast light on the size of apertures which individuals of different size are capable of egressing under such circumstances. Realistic evacuation drills of public buildings are both impracticable and prohibitively expensive and if undertaken, may themselves place participants at risk, and consequently this lack of knowledge may seriously undermine safety planning. In a real world setting, the demographic shift towards an older, larger and heavier global population mandates urgent re-consideration of design assumptions to accommodate people in contemporary society. In respect of historic buildings which cannot be re- 
designed, a burgeoning seniors' tourist market (Jang et al., 2009), may mean individuals who are most challenged by such environments are becoming increasingly prevalent. Perhaps the biggest challenge of all is striking the appropriate balance between encouraging access to cultural heritage while protecting personal safety. A knowledge of minimum egress apertures will inevitably form part of the understanding necessary to achieve this.

\section{KEY POINTS}

- Movement of individuals in crowd research models has generally not considered body size variability as a factor, which pivotally affects clearance space and passing ability.

- Research which has shaped our understanding of body space requirements requires updating to take account of increases in typical body size over recent decades.

- While men and women appear to perform broadly similarly with respect to wall egress, subtle differences in body shape affect the result.

- Future research should use anatomical size data from a contemporary population, and consider movement dynamics of narrow aperture egress within buildings.

\section{REFERENCES}

Allan, J.R. \& Ward, F.R.C. (1986). Aircrew equipment group report no. 528. Emergency exits for underwater escape from rotorcraft. Royal Air Force, Institute of Aviation Medicine. Farnborough, UK.

Bohannon, R.W. (1997). Comfortable and maximum walking speed of adults aged 20-79 years: reference values and determinants. Age and Ageing, 26, 15-19.

Franchak, J. \& Adolph, K. (2014a). Affordances as probabilistic functions: implications for development, perception, and decisions for action. Ecological Psychology, 26, 109-124. 
Franchak, J. \& Adolph, K. (2014b). Gut estimates: pregnant women adapt to possibilities for squeezing through doorways. Attention, Perception, \& Psychophysics 76, 460-72. doi: 10.3758/s13414-0130578-y.

Franchak, J.M., Celano, E.C., \& Adolph, K.E. (2012). Perception of passage through openings depends on the size of the body in motion. Experimental Brain Research 223, 301-310.

Fruin J.J. (1971). Designing for pedestrians: A level-of-service concept. Highway Research Record, Number 355: Pedestrians, Highway Research Board. Washington, D.C. pp1-15.

Galea, E. R., Sharp, G., Lawrence, P.J. \& Holden, R. (2008). Approximating the evacuation of the World Trade Center North Tower using computer simulation. Journal of Fire Protection Engineering, 18, 85-115.

Hackney, A.L. \& Cinelli, M.E. (2011). Action strategies of older adults walking through apertures. Gait \& Posture, 33, 733-736.

Helbing, D., Farkas, T., \& Vicsek, T. (2000). Simulating dynamical features of escape panic. Nature, 407, 487-490.

Hu, J., You, L., Zhang, H., Wei, J. \& Guo, Y. (2018). Study on queueing behaviour in pedestrian evacuation by extended cellular automata model. Physica A, 489, 112-127.

Iwasaki, S., \& Yamasoba, T. (2015). Dizziness and Imbalance in the Elderly: Age-related Decline in the Vestibular System. Aging and Disease, 6(1), 38-47. http://doi.org/10.14336/AD.2014.0128 Jang, S., Bai, B., Hu, C. \& Wu, C-M. (2009). Affect, travel motivation and travel intention: a senior market. Journal of Hospitality and Tourism Research, 33, 51-73.

Jin, C-J., Jiang, R., Yin, J-L., Dong, L-Y. \& Li, D. (2017). Simulating bi-directional pedestrian flow in a cellular automaton model considering the body-turning behaviour, Physica A., 482, 666-681. http://dx.doi.org/10.1016/j.physa.2017.04.117

Kozey, J.W., Brooks, C.J., Dewey, S.L., Brown, R.C., Howard, K.A., Drover, D., MacKinnon, S. \& McCabe, J. (2008). Effects of human anthropometry and personal protective equipment on space requirements. Occupational Ergonomics, 8, 67-79. 
Ledingham, R., Nevill, A.M. \& Stewart, A.D. Reproducibility of body volume assessments in survival clothing in fixed and portable scanning systems. Proceedings of the $4^{\text {th }} 3 D$ body Scanning Conference, Long Beach California, November 2013. pp. 355-359.

Loh, K.Y. \& Ogle, J. (2004). Age related visual impairment in the elderly. Medical Journal of Malaysia, 59, 562-569.

Manenti ,L., Manzoni, S., Vizzari, G., Ohtsuka, K. \& Shimura, K. (2010). Towards an agent-based proxemic model for pedestrian and group dynamic. In WOA 2010, volume 621 of CEUR Workshop Proceedings. CEUR-WS.org, 2010.

Nadadur, G. \& Parkinson, M.B. (2013). The role of anthropometry in designing for sustainability. Ergonomics, 56, 422-439.

Nicolas, A., Bouzat, S. \& Kuperman, M.N. (2017). Pedestrian flows through a narrow doorway: Effect of individual behaviours on the global flow of microscopic dynamics. Transportation Research Part $B, 99,30-43$.

Peebles, L. \& Norris, B. (2002). Adultdata: The handbook of adult anthropometric and strength measurements; data for design safety. Great Britain Department of Trade and Industry.; University of Nottingham. Institute for Occupational Ergonomics.

Pheasant, S. (2003). Bodyspace: Anthropometry, Ergonomics and the Design of Work $2^{\text {nd }}$ Ed.. London: Taylor \& Francis.

Qiu, F. \& Hu, X. (2010). Modeling group structures in pedestrian crowd simulation. Simulation Modelling Practice and Theory, 18, 190-205.

Schadschneider A., Klingsch W., Klüpfel H., Kretz T., Rogsch C. \& Seyfried A. (2011). Evacuation Dynamics: Empirical Results, Modeling and Applications. In: Meyers R. (eds) Extreme Environmental Events. Springer, New York, NY.

Spyropoulos, P., Pisciotta, J.C., Pavlou, K.N., Cairns, M.A. \& Simon, S.R. (1991). Biomechanical gait analysis in obese men. Archives of Physical Medicine \& Rehabilitation, 72, 1065-1070. 
Stewart, A., Ledingham, R., Furnace, G. \& Nevill, A. (2015). Body Size and ability to pass through a restricted space: Observations from 3D scanning of 210 male UK Offshore Workers. Applied Ergonomics, 51, 358-362

Stewart, A.D. (2016). Passing ability and clearance space: the overlooked factor in human movement modelling Invited commentary for the International Journal of Public Health and Safety, 1, 115.

Stewart, A., Marfell-Jones, M., Olds, T. \& de Ridder, H. (2011). International Standards for Anthropometric Assessment. International Society for the Advancement of Kinanthropometry, Lower Hutt, New Zealand. 125pp.

Stewart, A. D. \& Hume, P.A. (2014). Bideltoid Breadth Measurement. J.E. Lindsay Carter Kinanthropometry Archive https://www.sprinz.aut.ac.nz/clinics/i.e.-lindsay-carterkinanthropometry-clinic/archive

Stewart, A. \& Campbell, C. (2018). Moving around monuments. The Ergonomist 567, 18-21.

Stewart, A. D. \& Hume, P.A. (2015). Chest Depth Measurement. J.E. Lindsay Carter Kinanthropometry Archive https://www.sprinz.aut.ac.nz/clinics/i.e.-lindsay-carter-kinanthropometry-clinic/archive

Stewart, A., Elyan, E., Isaacs, J. McEwen, L. \& Wilson, L. (2017). The effect of person order on egress time: a simulation model of evacuation from a Neolithic visitor attraction. Human Factors, 59, 1222-1232. Doi: 10.1177/0018720817729608

Stewart, A., Ledingham, R., Furnace, G., Schranz, N. \& Nevill, A. (2016). The ability of UK offshore workers of different body size and shape to egress through a restricted window space. Applied Ergonomics 55, 226-233. DOI: 10.1016/j.apergo.2015.11.005.

Still, G. K. (2013). Introduction to Crowd Science. London: CRC Press ISBN 978-1-4665-7964-4.

Tajima, Y., Takimoto, K. \& Nagatani, T. (2001). Scaling of pedestrian channel flow with a bottleneck. Physica A, 294, 257-268.

Tang, F. \& Ren, A. (2008). Agent-based evacuation model incorporating fire scene and building geometry. Tsinghua Science and Technology 13, 708-714. 
Toomey, C., McCreesh, K., Leahy, S. \& Jakeman, P. (2011). Technical considerations for accurate measurement of subcutaneous adipose tissue thickness using B-mode ultrasound Ultrasound, 19, 91-96.

Warren, W.H. (2007). Action-scaled information for the visual control of locomotion. In: Pepping, G.J. \& Grealy, M.L. (eds.) Closing the gap: the scientific writings of David N. Lee. Erlbaum, Mahwah, N.J. pp 253-268.

Warren, W.J. \& Whang, S. (1987). Visual guidance of walking through apertures: body-scaled information and affordances. Journal of Experimental Psychology: Human Perception and Performance 13, 371-383.

Willis, A., Gjersoe, N., Havard, C., Kerridge, J. \& Kukla, R. (2004). Human movement behaviour in urban spaces: implications for the design and modelling of effective pedestrian environments. Environment and Planning B: Planning and Design, 31, 805-828.

Wilson, R. (2008). Factors influencing passenger evacuation from smaller transport aircraft including the operation of the Type III exit. PhD Thesis, University of Cranfield.

Zhao, Y., Li, M., Lu, X., Tian, L., Yu, Z., Huang, K., Wang, Y. \& Li, T. (2017). Optimal layout design of obstacles for panic evacuation using differential evolution. Physica A, 465, 175-194.

Arthur Stewart PhD (University of Edinburgh, 1999) is a senior researcher in the School of Health Sciences at Robert Gordon University. He is a criterion anthropometrist with the International Society for the Advancement of Kinanthropometry (ISAK), Fellow of the Chartered Institute of Ergonomics \& Human Factors, with which he is also a Chartered Ergonomist and Human Factors Specialist. He received the William Floyd Award for outstanding and innovative contributions to ergonomics and human factors in 2018, and he continues to research body size, function and movement within restricted space settings. 
Alan Nevill PhD (University of Bradford, 1975) is the Research Professor in the Faculty of Education Health and Wellbeing, Wolverhampton University (specialization in biostatistics applied to health, sport and exercise sciences). His most recent research specializes in multilevel and allometric modelling of large data sets, analyzing human health and performance associated with body size. He is former Editor-in-Chief of the Journal of Sports Sciences, and has been a Fellow of the Royal Statistical Society for over 40 years.

Christopher Johnson is an undergraduate in Applied Sports and Exercise Science at Robert Gordon University. He is a level 2 certified anthropometrist with the International Society for the Advancement of Kinanthropometry, and assumed operational responsibility for the project while on industrial placement to RGU's Scanning and Ergonomics Laboratory. 